\title{
The central nervous system tumor methylation classifier changes neuro- oncology practice for challenging brain tumor diagnoses and directly impacts patient care
}

Shirin Karimi ${ }^{2+}$, Jeffrey A. Zuccato ${ }^{1,2+}$, Yasin Mamatjan ${ }^{2}$, Sheila Mansouri ${ }^{2}$, Suganth Suppiah ${ }^{1,2}$, Farshad Nassiri ${ }^{1,2}$, Phedias Diamandis ${ }^{2,3}$, David G. Munoz ${ }^{4}$, Kenneth D. Aldape $2,5^{*}$ and Gelareh Zadeh ${ }^{1,2^{*}}$

\begin{abstract}
Background: Molecular signatures are being increasingly incorporated into cancer classification systems. DNA methylation-based central nervous system (CNS) tumor classification is being recognized as having the potential to aid in cases of difficult histopathological diagnoses. Here, we present our institutional clinical experience in integrating a DNA-methylation-based classifier into clinical practice and report its impact on CNS tumor patient diagnosis and treatment.

Methods: Prospective case review was undertaken at CNS tumor board discussions over a 3-year period and 55 tumors with a diagnosis that was not certain to two senior neuropathologists were recommended for methylation profiling based on diagnostic needs. Tumor classification, calibrated scores, and copy number variant (CNV) plots were obtained for all 55 cases. These results were integrated with histopathological findings to reach a final diagnosis. We retrospectively reviewed each patient's clinical course to determine final neuro-pathology diagnoses and the impact of methylation profiling on their clinical management, with a focus on changes that were made to treatment decisions.

Results: Following methylation profiling, 46 of the 55 (84\%) challenging cases received a clinically relevant diagnostic alteration, with two-thirds having a change in the histopathological diagnosis and the other one-third obtaining clinically important molecular diagnostic or subtyping alterations. WHO grading changed by $27 \%$ with two-thirds receiving a higher grade. Patient care was directly changed in 15\% of all cases with major changes in clinical decision-making being made for these patients to avoid unnecessary or insufficient treatment.

Conclusions: The integration of methylation-based CNS tumor classification into diagnostics has a substantial clinical benefit for patients with challenging CNS tumors while also avoiding unnecessary health care costs. The clinical impact shown here may prompt the expanded use of DNA methylation profiling for CNS tumor diagnostics within prominent neuro-oncology centers globally.
\end{abstract}

Keywords: Central nervous system, Neuro-oncology, Epigenetics, Translational research

\footnotetext{
* Correspondence: kenneth.aldape@nih.gov; gelareh.zadeh@uhn.ca

${ }^{\dagger}$ Shirin Karimi and Jeffrey A. Zuccato are co-first authors

${ }^{2}$ MacFeeters-Hamilton Center for Neuro-Oncology, Princess Margaret Cancer

Center, Princess Margaret Cancer Research Tower, 101 College Street, 14th

floor, Room 601, Toronto, ON M5G 1L7, Canada

'Division of Neurosurgery, University Health Network, University of Toronto,

Toronto, Ontario, Canada

Full list of author information is available at the end of the article
}

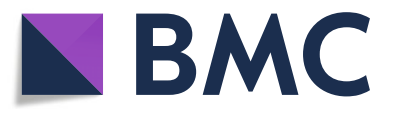

(c) The Author(s). 2019 Open Access This article is distributed under the terms of the Creative Commons Attribution 4.0 International License (http://creativecommons.org/licenses/by/4.0/), which permits unrestricted use, distribution, and reproduction in any medium, provided you give appropriate credit to the original author(s) and the source, provide a link to the Creative Commons license, and indicate if changes were made. The Creative Commons Public Domain Dedication waiver (http://creativecommons.org/publicdomain/zero/1.0/) applies to the data made available in this article, unless otherwise stated. 


\section{Introduction}

The classification and diagnosis of central nervous system (CNS) tumors, as with all neoplastic processes, is essential in determining optimal patient treatment decisions. Histopathological features have traditionally been used to classify tumors using World Health Organization (WHO) criteria [1]. However, in the past decade, the value of integrating molecular alterations into WHO classification criteria has been widely recognized [2-5]. Specific molecular features that have been incorporated into the 2016 WHO classifications include IDH mutation and $1 \mathrm{p} / 19 \mathrm{q}$ co-deletion statuses for gliomas as well as definitions of subtypes for medulloblastomas and ependymomas $[1,6]$.

Genome-wide DNA methylation differences have been used to determine the cell of origin and classify many non-CNS tumors [7-10]. Additionally, a recent seminal publication has demonstrated its utility in classifying CNS tumors with improved diagnostic accuracy in comparison to the standard of care histopathological analysis and single molecular tests [11]. This CNS tumor classifier was built based on methylation profiling of 2682 brain tumor cases across 82 different tumor subtypes and then it was applied to 1104 additional cases to determine diagnostic utility. Of these 1104 cases in their cohort, $12 \%$ received a new integrated diagnosis when methylation profiling results were added to standard of care histopathological testing. To date, however, the impact of methylation classifier on clinical outcome has not been well established.

In this study, we describe a single institutional experience of implementing the CNS tumor methylation-based classifier into clinical practice. Through key case descriptions, we illustrate the impact on patient outcomes after integrating methylation profiling results in their care. A substantial proportion of patients (84\%) had important treatment decision changes made after methylation profiling that modified their CNS tumor diagnosis. A significant percentage (15\%) had a resulting change in the clinical treatment course. The value of rapidly adopting and integrating the methylation-based CNS tumor classifier into clinical practice is highlighted in this work.

\section{Materials and methods}

\section{Patient cohort selection}

Between November 1, 2015 and September 30, 2018, all brain tumor cases reviewed at UHN multidisciplinary CNS tumor board meetings and selected for methylation analysis were included in this study. Reasons to select cases included (1) challenging diagnoses including those with unusual morphological features where two independent experienced neuropathologists were uncertain of the final diagnosis based on histopathological assessment and existing molecular markers, (2) diffuse gliomas with immunohistochemistry (IHC) antibody-negative mutant-IDH1 (R132H) status to determine final IDH status, (3) ependymomas or medulloblastomas requiring molecular subtyping, (4) indeterminant fluorescence in situ hybridization (FISH) results for $1 \mathrm{p} / 19 \mathrm{q}$ co-deletion status in diffuse gliomas needing validation, and (5) discrepancies between clinical or imaging features and histopathological diagnoses that raised concern for alternative diagnoses. All standard of care FISH, IHC, and other molecular testing were completed prior to methylation profiling consideration as is routine practice at our institution.

\section{DNA methylation analysis}

Tumor samples from formalin-fixed paraffin-embedded tissue specimens including five scrolls or at least ten unstained slides with 5-10 $\mu \mathrm{m}$ in thickness were utilized and areas with the available tumor cellularity over $70 \%$ were preferred. Extracted DNA (150-500 ng) was bisulfite-converted (EZ DNA Methylation Kit, Zymo Research D5001). Samples were processed in our institutional genomics facility that combined samples from multiple sources to process in batches of 12 for the Illumina Infinium HumanMethylation450 BeadChip (450k) array or 8 for the MethylationEPIC BeadChip (850k) array. Standard quality controls confirmed adequate tumor purity/quality, bisulfite conversion, and DNA quality. IDAT files were uploaded to either version $11 \mathrm{~b} 2$ or 11b4 of the online CNS tumor methylation classifier (https://www.molecularneuropathology.org) and reports were produced as shown by Capper et al. [11].

\section{Diagnostic integration}

The methylation results from the classifier include the methylation classification, calibrated scores reflecting prediction scores of methylation class diagnoses, and chromosomal copy number variation (CNV) plots generated from raw methylation data. Calibrated scores were assessed based on the German Cancer Research Center protocol with a preference for calibrated scores $\geq 0.9$ but inclusion between 0.3 and 0.9 in the context of low tumor-cell content [12]. Deletions, amplifications, and losses or gains were assessed visually in the $\mathrm{CNV}$ plots for specific diagnostic alterations (e.g., 1p/19q whole arm loss for oligodendroglioma) using the approach described by the German Cancer Research Center group [13]. MGMT methylation was assessed by the classifier using a methylation probability cutoff of $0.3582[12,14]$. The diagnostic workflow included a re-evaluation of original histopathology as well as all standard of care molecular testing results, integration of these results with methylation classification and $\mathrm{CNV}$ plots to determine the final diagnosis, and feedback of any diagnostic 
changes to treating clinicians in tumor board discussions.

\section{Clinical data collection}

Data that were collected both prospectively and retrospectively were needed to determine the clinical course and oncological outcomes. Fields collected included demographics, preoperative clinical factors, neuroimaging findings, surgical details, pathology results, patient treatment decisions made prior to and following completion of methylation profiling, treatment complications, and follow-up clinical status.

\section{Results}

\section{Cohort characteristics}

Between November 1, 2015, and September 30, 2018, a total of 1670 operative cases were reviewed at UHN CNS tumor board discussions. Of all cases, 66 represented diagnostic challenges and thereby fit the criteria for methylation profiling. A total of 55 cases were included in this study with 11 cases excluded due to insufficient tumor quantity/quality or no classifier tumor match. The median turnaround time for methylation profiling was 25 days. Clinical characteristics of the cohort along with reasons to select patients for methylation profiling are shown in Table 1. The average age was 41 years (range $=18-71$ ) with equal distribution across sexes and the majority having supratentorial tumors. Three-quarters of patients remain alive and average follow-up is over 2 years. The key reason for identifying a case as challenging included an uncertain diagnosis by two expert neuropathologists with differential pathological diagnoses being given in 20/55 (36\%) cases and unusual morphological features being present for the proposed diagnosis in 13/55 (24\%). The distribution of cases across WHO tumor types reflects a general CNS oncology practice and is shown in Table 2 , with the majority being diffuse gliomas.

\section{Diagnostic impact of methylation profiling}

Table 3 shows that a diagnostic alteration made between initial pathological diagnosis and final integrated molecular diagnoses using methylation profiling was observed in $84 \%$ of cases $(46 / 55)$. These cases include $24 \%$ $(13 / 55)$ with a change in the diagnostic entity, 31\% (17/ $55)$ with a resolved differential diagnosis, and $29 \%$ (16/ $55)$ having clinically relevant molecular subtyping determinations. The classifier changed or finalized the WHO grade in $27 \%$ (15/55), two-thirds of which were upgraded to a higher grade. Figure 1 summarizes the diagnostic impact in those cases with definitive changes in top diagnoses.

Evidence of an IDH mutation was identified in 9 of 24 diffuse glioma cases for which the $\mathrm{R} 132 \mathrm{H}$ mutant-
Table 1 Cohort characteristics

\begin{tabular}{|c|c|c|c|}
\hline \multicolumn{4}{|l|}{ Characteristic } \\
\hline & & Mean & Range \\
\hline \multicolumn{2}{|l|}{ Age (years) ${ }^{a}$} & 41.0 & $18-71$ \\
\hline \multicolumn{2}{|c|}{ Follow-up since surgery (years) ${ }^{b}$} & 2.1 & $0.1-15.5$ \\
\hline & & $N$ & $\%$ \\
\hline Gender $^{\mathrm{a}}$ & Male & 25 & 49 \\
\hline \multirow[t]{3}{*}{ Tumor location $^{b}$} & Supratentorial & 38 & 81 \\
\hline & Infratentorial, intracranial & 7 & 15 \\
\hline & Spinal, intradural & 2 & 4 \\
\hline \multicolumn{2}{|l|}{$\begin{array}{l}\text { Surgery for recurrent } \\
\text { tumor }^{\mathrm{b}}\end{array}$} & 8 & 17 \\
\hline Extent of resection $^{d}$ & Subtotal resection & 30 & 68 \\
\hline \multirow[t]{2}{*}{ Current status $^{b}$} & Well/stable disease & 35 & 74 \\
\hline & Palliative/deceased & 12 & 26 \\
\hline \multirow[t]{6}{*}{$\begin{array}{l}\text { Indication for } \\
\text { methylation profiling }\end{array}$} & $\begin{array}{l}\text { Challenging diagnosis with } \\
\text { differential given }\end{array}$ & 20 & 36 \\
\hline & $\begin{array}{l}\text { Diagnoses without classical } \\
\text { features }\end{array}$ & 13 & 24 \\
\hline & $\begin{array}{l}\text { Final determination of IDH } \\
\text { status }\end{array}$ & 11 & 20 \\
\hline & Molecular subtyping & 4 & 7 \\
\hline & $\begin{array}{l}\text { Final determination of } 1 p / 19 q \\
\text { co-deletion status }\end{array}$ & 4 & 7 \\
\hline & $\begin{array}{l}\text { Clinical discrepancy with } \\
\text { pathologic diagnosis }\end{array}$ & 3 & 5 \\
\hline \multirow[t]{5}{*}{ Initial WHO grade ${ }^{e}$} & I & 8 & 15 \\
\hline & $\|$ & 15 & 27 \\
\hline & III & 13 & 24 \\
\hline & IV & 15 & 27 \\
\hline & Not graded & 4 & 7 \\
\hline
\end{tabular}

specific antibody was negative (6/9 showed ATRX loss by $\mathrm{IHC}$ and $3 / 9$ were $1 \mathrm{p} / 19 \mathrm{q}$ co-deleted by FISH), presumably reflecting non-canonical IDH mutations. The IDH1 mutation status in six cases determined by positive IHC staining for IDH1 (R132H)-specific antibody was confirmed by methylation analysis. $\mathrm{CNV}$ analyses also confirmed two of five 1p/19q co-deletions identified by FISH testing in oligodendrogliomas with the other three co-deletions by FISH being false positives. MGMT methylation status was identified by the classifier in all cases. Methylation profiling identified one MGMT methylated diffuse glioma with inconclusive MGMT pyrosequencing results and the results between both modalities were consistent in all of seven other diffuse gliomas that underwent pyrosequencing. Subtyping 
Table 2 Initial histopathological diagnoses

\begin{tabular}{|c|c|c|c|}
\hline \multicolumn{2}{|c|}{ Tumor type $(n=55)$} & \multirow{2}{*}{$\frac{N}{4}$} & \multirow{2}{*}{$\frac{\%}{7}$} \\
\hline Diffuse & Diffuse astrocytoma, IDH mutant & & \\
\hline & Diffuse astrocytoma, IDH1 (R132H) negative & 2 & 4 \\
\hline & Anaplastic astrocytoma, IDH mutant & 2 & 4 \\
\hline & Anaplastic astrocytoma, IDH1 (R132H) negative & 3 & 5 \\
\hline & $\begin{array}{l}\text { Oligodendroglioma, IDH1 (R132H) negative, 1p/ } \\
\text { 19q co-deleted }\end{array}$ & 2 & 4 \\
\hline & $\begin{array}{l}\text { Anaplastic oligodendroglioma, IDH1 (R132H) } \\
\text { negative, } 1 \mathrm{p} / 19 \mathrm{q} \text { co-deleted }\end{array}$ & 3 & 5 \\
\hline & Glioblastoma, IDH1 (R132H) negative & 11 & 20 \\
\hline & Glioma NOS & 3 & 5 \\
\hline & Low grade glioma & 1 & 2 \\
\hline & Diffuse low grade glioma & 1 & 2 \\
\hline \multirow{3}{*}{$\begin{array}{l}\text { Other } \\
\text { astrocytic }\end{array}$} & Pilocytic astrocytoma & 1 & 2 \\
\hline & PXA & 1 & 2 \\
\hline & Anaplastic PXA & 2 & 4 \\
\hline \multirow[t]{3}{*}{ Ependymal } & Subependymoma & 2 & 4 \\
\hline & Ependymoma & 1 & 2 \\
\hline & Anaplastic ependymoma & 3 & 5 \\
\hline $\begin{array}{l}\text { Choroid } \\
\text { plexus }\end{array}$ & Atypical choroid plexus papilloma & 1 & 2 \\
\hline \multirow[t]{2}{*}{ Neuronal } & Dysembryoplastic neuroepithelial tumor & 1 & 2 \\
\hline & Ganglioglioma variant & 2 & 4 \\
\hline Embryonal & Medulloblastoma & 3 & 5 \\
\hline Nerves & Schwannoma & 1 & 2 \\
\hline Meningioma & Atypical meningioma & 1 & 2 \\
\hline Mesenchymal & SFT/hemangiopericytoma & 1 & 2 \\
\hline \multirow[t]{2}{*}{ Metastatic } & Melanocytic lesion NOS & 1 & 2 \\
\hline & Metastatic high-grade NE neoplasm & 1 & 2 \\
\hline $\begin{array}{l}\text { Non- } \\
\text { neoplastic }\end{array}$ & Meningioangiomatosis & 1 & 2 \\
\hline
\end{tabular}

NOS not otherwise specified, PXA pleomorphic xanthoastrocytoma, SFT solitary fibrous tumor, $N E$ neuroendocrine

identified two SHH-A medulloblastomas and one from group 4 as well as two PFB ependymomas, one initially diagnosed as a low-grade glioma. The IDH wildtype glioblastoma cases were classified in the following subclasses: mesenchymal (10), RTK II (3), MYCN (1), and H3.3G34 (1) [3, 11].

\section{The impact of methylation profiling on clinical management}

We defined a substantial clinical impact as a new diagnosis based on methylation profiling that would alter treatment decisions. Specific alterations include management decisions on surveillance imaging postoperatively as well as delivery of radiotherapy, chemotherapy, or targeted therapy. Table 4 summarizes the substantial number of patients $(15 \%)$ whose treatment
Table 3 Diagnostic impacts of methylation profiling

\begin{tabular}{|c|c|c|c|}
\hline Category & & $N$ & $\%$ \\
\hline \multirow[t]{4}{*}{ Diagnostic effect $^{\mathrm{e}}$} & Change in diagnosis & 13 & 24 \\
\hline & Resolution of differential diagnosis & 17 & 31 \\
\hline & Molecular refinement & 16 & 29 \\
\hline & Diagnostic validation & 9 & 16 \\
\hline \multirow[t]{4}{*}{ WHO grade change ${ }^{e}$} & Upgrade & 10 & 18 \\
\hline & Downgrade & 3 & 5 \\
\hline & Assign grade & 2 & 4 \\
\hline & Unchanged & 40 & 73 \\
\hline \multirow{4}{*}{$\begin{array}{l}\text { All molecular } \\
\text { refinements }\end{array}$} & Change in IDH mutation status & 9 & 16 \\
\hline & $\begin{array}{l}\text { Final determination of an unclear IDH } \\
\text { mutation status }\end{array}$ & 23 & 42 \\
\hline & Identification of molecular subtype & 20 & 36 \\
\hline & $\begin{array}{l}\text { Determination of } 1 p / 19 q \text { co-deletion } \\
\text { status }\end{array}$ & 6 & 11 \\
\hline
\end{tabular}

plan and adjuvant therapy were or would be changed after taking the new integrated diagnosis into consideration in management decisions. The median turnaround time for these specific cases was 32 days and results were made available prior to decision making regarding treatment. The seven cases are highlighted below:

\section{Case 1}

A 20-year old female presented with seizures and imaging revealed a right frontal low-grade-infiltrative lesion consistent with a glioma. A gross total resection was achieved at surgery. The histopathological diagnosis was a glioma, not otherwise specified (NOS) without WHO grading which was IDH1 (R132H) antibody-negative, 1p/19q noncodeleted, and ATRX retained. Moderately severe nuclear atypia, areas of morphologically oligodendroglial-like differentiation, and focal microvascular proliferation raised the suspicion for a high-grade glioma including glioblastoma, although the tumor showed no evidence of necrosis and it was not mitotically active. After multidisciplinary tumor board consensus, the treatment offered was concurrent chemo-radiotherapy plus adjuvant temozolomide.

Methylation profiling was performed given the uncertainty in the diagnosis and grading of the tumor. The methylation classifier indicated that the tumor was a dysembryoplastic neuroepithelial tumor (DNET) with a calibrated score of 0.9 , and this methylation class diagnosis was supported by a relatively flat CNV plot with no evidence of significant gene or chromosomal alterations. Two independent neuropathologists concurred with the new diagnosis upon review of the histopathology of the tumor, including the H\&E stain and CNV plot shown in Fig. 2. Accordingly, the new management based on consensus of the 


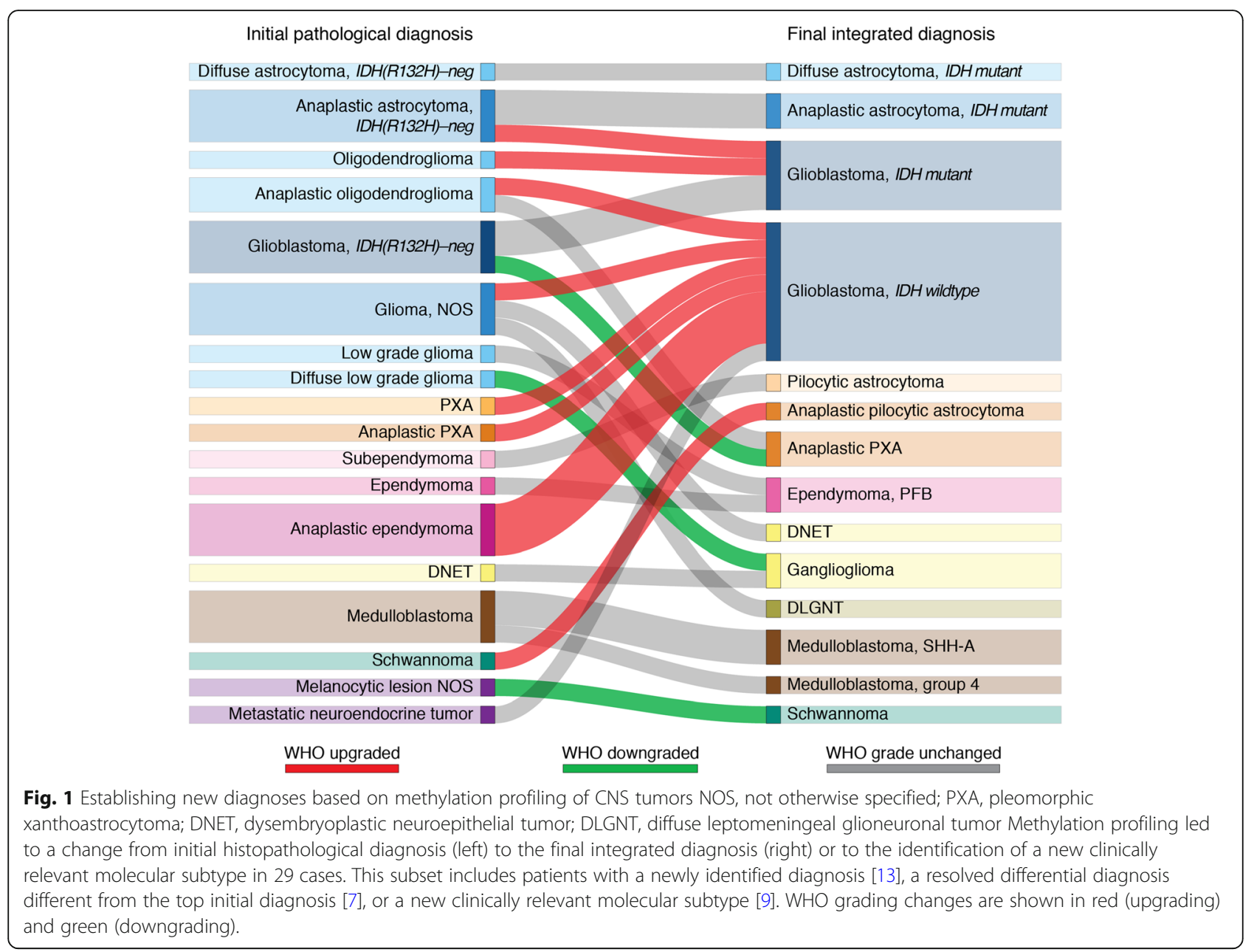

tumor board discussion with the neuro-oncology team was observation and close surveillance imaging. This avoided cranial radiation for a young patient and she remains stable 13 months following initial diagnosis.

\section{Case 2}

A 23-year-old male presented with seizures and hemiplegia and imaging demonstrated a recurrent left temporal lesion. Following resection, the lesion was diagnosed histopathologically as a $1 \mathrm{p} / 19 \mathrm{q}$ co-deleted anaplastic oligodendroglioma although it was noted that the IDH1 (R132H) antibody (IHC) was negative. With this diagnosis, the patient was treated with radiotherapy and was planned to receive PCV chemotherapy. Methylation profiling was pursued to confirm the diagnosis and determine the final IDH status. The tumor matched to the (anaplastic) pleomorphic xanthoastrocytoma (PXA) methylation class with a calibrated score of 0.94 . The CNV plot identified a homozygous CDKN2A deletion and also confirmed that the proposed $1 \mathrm{p} / 19 \mathrm{q}$ codeletion by FISH testing was a false positive. Based on this diagnosis a significant change in treatment was made to hold PCV therapy and avoid the related side effect profile. The patient remains stable 14 months after surgery.

\section{Case 3}

A 25-year-old female presented with seizures and a recurrent right temporal tumor that was diagnosed as an oligodendroglioma eight years prior, with no specific molecular analysis performed. Surveillance imaging was carried out and at recurrence, the patient was referred to our institution for a second resection. The histopathology of the tumor resected in the second surgery showed a glioma, NOS that was not $1 \mathrm{p} / 19 \mathrm{q}$ co-deleted by FISH testing and IDH1 (R132H) was negative by IHC. Based on the anaplastic features and absence of IDH1 $(\mathrm{R} 132 \mathrm{H})$ mutation, the management consensus after review in a tumor board discussion was concurrent chemoradiotherapy plus adjuvant temozolomide. Methylation profiling was initiated due to an unclear and challenging diagnosis. The tumor matched to the diffuse leptomeningeal glioneuronal tumor (DLGNT) methylation class with a calibrated score of 0.99. The CNV plot showed an isolated loss of 
Table 4 Clinical summary of cases with a significant methylation-mediated impact on patient care

\begin{tabular}{|c|c|c|c|c|c|}
\hline $\begin{array}{l}\text { Case } \\
\text { no. }\end{array}$ & $\begin{array}{l}\text { Initial pathology } \\
\text { (*differential) }\end{array}$ & Initial treatment plan & Integrated diagnosis & New treatment plan & Methylation profiling impact \\
\hline 1 & $\begin{array}{l}\text { Glioma NOS } \\
\text {-IDH1 (R132H)-neg, } \\
\text { high-grade features }\end{array}$ & $\begin{array}{l}\text { Offered FSRT/TMZ \& } \\
\text { adjuvant TMZ }\end{array}$ & DNET & Observation & $\begin{array}{l}\text { 1) Avoided unnecessary treatment } \\
\text { 2) Resolved anxiety due to initial } \\
\text { diagnosis/treatment }\end{array}$ \\
\hline 2 & $\begin{array}{l}\text { Anaplastic } \\
\text { oligodendroglioma } \\
\text {-IDH1 (R132H)-neg, } \\
\text { 1p/19q-codeletion }\end{array}$ & $\begin{array}{l}\text { 1) Received FSRT } \\
\text { 2) Planned for PCV }\end{array}$ & Anaplastic PXA & $\begin{array}{l}\text { 1) Hold PCV } \\
\text { 2) Observe }\end{array}$ & Avoided unnecessary treatment \\
\hline 3 & $\begin{array}{l}\text { Glioma NOS } \\
\text {-IDH1 (R132H)-neg, } \\
\text { anaplastic features }\end{array}$ & $\begin{array}{l}\text { Offered FSRT/TMZ } \\
\text { and adjuvant TMZ }\end{array}$ & DLGNT & Observation & Avoided unnecessary treatment \\
\hline 4 & $\begin{array}{l}\text { 1) } \mathrm{GBM}^{*} \\
\text { 2) Anaplastic PXA } \\
\text { - IDH1 (R132H)-neg, BRAF } \\
\text { (V600E)-mut, high-grade } \\
\text { features }\end{array}$ & $\begin{array}{l}\text { FSRT/TMZ and adjuvant } \\
\text { TMZ }\end{array}$ & Anaplastic PXA & $\begin{array}{l}\text { Surgery, chemotherapy, } \\
\text { and BRAF inhibitor after } \\
\text { recurrence }\end{array}$ & $\begin{array}{l}\text { 1) Resolved depression due to unclear } \\
\text { diagnosis } \\
\text { 2) Avoided potential medical assisted } \\
\text { death due to diagnosis given }\end{array}$ \\
\hline 5 & $\begin{array}{l}\text { Schwannoma } \\
\text {-SOX10-pos, S100-pos, Ki- } \\
6710 \%\end{array}$ & FSRT & $\begin{array}{l}\text { Anaplastic pilocytic } \\
\text { astrocytoma } \\
\text {-Malignant glial tumor }\end{array}$ & $\begin{array}{l}\text { Provided full craniospinal } \\
\text { radiation at recurrence }\end{array}$ & $\begin{array}{l}\text { Received potentially insufficient initial } \\
\text { treatment }\end{array}$ \\
\hline 6 & $\begin{array}{l}\text { 1) } P A^{*} \\
\text { 2) Other high-grade } \\
\text { gliomas } \\
\text { - IDH1 (R132H)-neg, BRAF } \\
\text { (V600E)-neg }\end{array}$ & $\begin{array}{l}\text { Considered reduced } \\
\text { dosing for FSRT/TMZ } \\
\text { \& adjuvant TMZ }\end{array}$ & GBM, IDH wildtype & $\begin{array}{l}\text { Treatment fully } \\
\text { completed }\end{array}$ & $\begin{array}{l}\text { Avoided possible insufficient initial } \\
\text { treatment }\end{array}$ \\
\hline 7 & $\begin{array}{l}\text { Metastatic high-grade } \\
\text { neuro-endocrine tumor } \\
\text {-TTF1-pos, IDH1 (R132H)- } \\
\text { neg, well demarcated }\end{array}$ & $\begin{array}{l}\text { 1) SRS post-op } \\
\text { 2) FSRT and cisplatin/ } \\
\text { etopside for 1st } \\
\text { recurrence } \\
\text { 3) Surgery and WBRT } \\
\text { for second recurrence }\end{array}$ & GBM, IDH wildtype & $\begin{array}{l}\text { Temozolomide provided } \\
\text { after second recurrence }\end{array}$ & $\begin{array}{l}\text { 1) Received insufficient treatment and } \\
\text { recurred } \\
\text { 2) May have avoided unnecessary } \\
\text { invasive biopsies }\end{array}$ \\
\hline
\end{tabular}

GBM glioblastoma, PXA pleomorphic xanthoastrocytoma, DLGNT diffuse leptomeningeal glioneuronal tumor, NOS not otherwise specified, DNET dysembryoplastic neuroepithelial tumor, SRS single-dose stereotactic radiosurgery, FSRT fractionated stereotactic radiotherapy, TMZ temozolomide, $R T$ radiotherapy

chromosome 1 . With the change in diagnosis, the new consensus on management after re-review at the neurooncology tumor board discussion was surveillance imaging and observation with no adjuvant treatment being given. The patient and imaging remain stable over 22 months.

\section{Case 4}

A 26-year-old female presented with seizures and a left temporal lesion called an astrocytoma, PXA, or other glioma based on MRI features. Following gross-total resection, the histopathological diagnosis was that of glioblastoma versus anaplastic PXA, and the tumor had high-grade morphological features, a BRAF V600E mutation, and was IDH1 (R132H) negative. Based on the uncertainty in differential diagnosis and concerning features on imaging for a high-grade lesion, the consensus on treatment was concurrent chemoradiotherapy plus adjuvant temozolomide. She suffered from considerable depression related to the possibility that she may have a glioblastoma and she considered medical assisted death due to this. Methylation profiling was pursued because of the unclear differential diagnosis and the deterioration in her clinical emotional status. The methylation class of the tumor was that of an (anaplastic) PXA with a calibrated score of 0.63. CNV plotting showed a homozygous CDKN2A loss and no other CNV findings consistent with glioblastoma. This classifier result and the calibrated score was interpreted as has been described by Capper et al. as supportive of the PXA diagnosis with additional confirmation from the BRAF mutation and homozygous CDKN2A loss [12]. The patient has since received redo-surgery, chemotherapy, and a BRAF inhibitor for recurrence. She is stable on the BRAF inhibitor after recurrence now 3 years since diagnosis and, notably, no longer pursuing medical assisted death.

\section{Case 5}

A 45-year-old male presented with sensorineural hearing loss and imaging revealed a left CP angle tumor considered a hemangiopericytoma versus schwannoma on MRI. After subtotal resection it was diagnosed as a SOX-10/S100 positive schwannoma with ancient change and rare mitotic activity along with a high Ki-67 of $10 \%$. Accordingly, he received postoperative radiotherapy. He then progressed soon after surgery with a new cerebellar nodule as well as spinal leptomeningeal disease which 

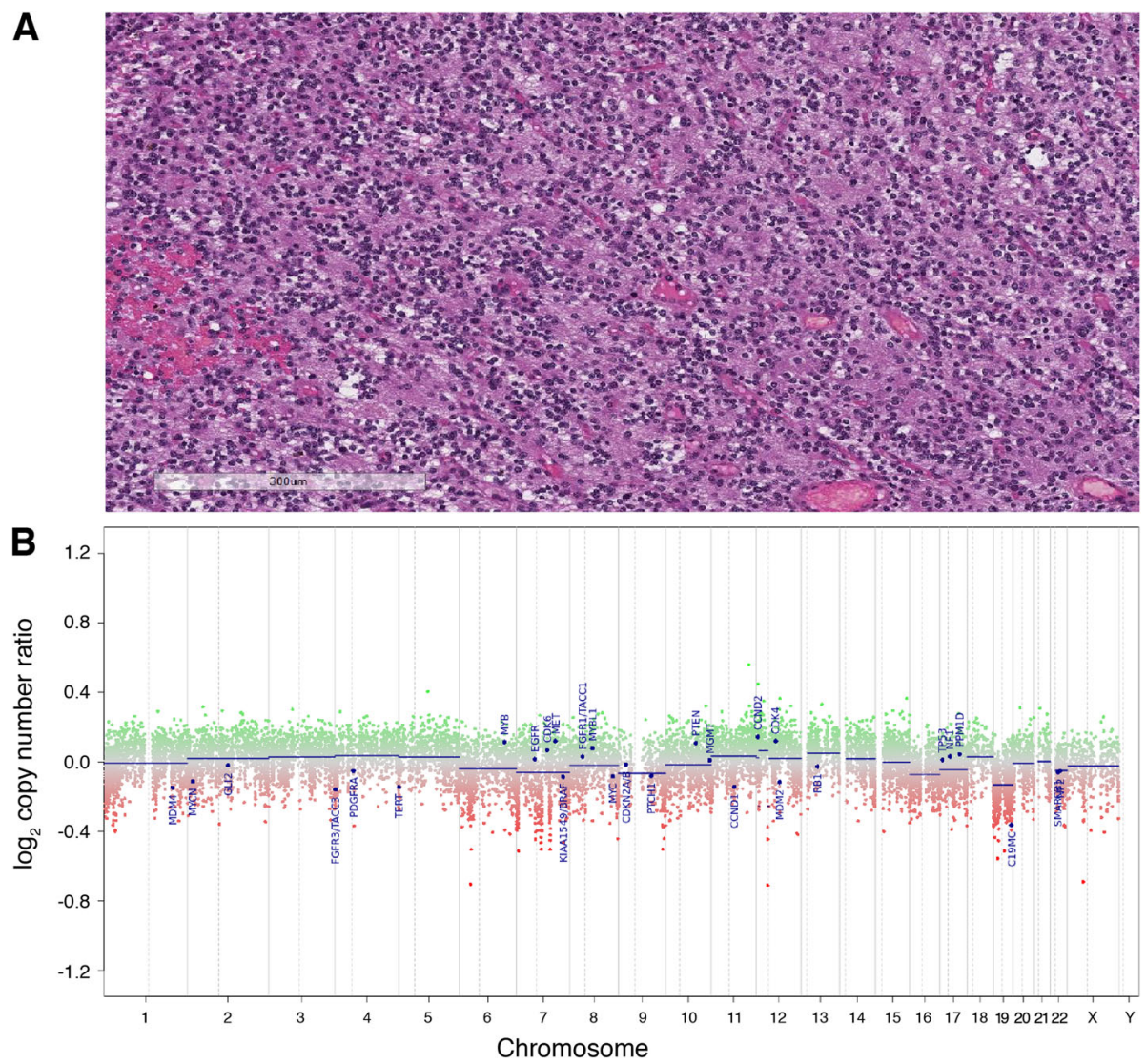

Fig. 2 Histopathology and CNV plot for the tumor in Case 1 H\&E stain and CNV plot for Case 1. a Hematoxylin and eosin stain of the tumor diagnosed as a Glioma, NOS with high-grade features and IDH1 (R132H) negative testing. b Relatively flat CNV plot supporting the integrated diagnosis of a dysembryoplastic neuro-epithelial tumor (DNET)

showed high-grade features on subsequent biopsy. Given the unusual clinical presentation, methylation profiling was performed. The tumor was matched to the class of an anaplastic pilocytic astrocytoma with a calibrated score of 0.4 and there was a chromosome 7 gain on the $\mathrm{CNV}$ plot. Given that this tumor sample sent for methylation profiling had very low tumor cellularity, this result was assessed as described by Capper et al. for intermediate-range calibrated scores with low tumor purity [12]. This result was thereby interpreted as suggesting that the tumor was more aligned with a malignant glial tumor than the initial diagnosis of a schwannoma. As the clinical presentation was also more consistent with that of a malignant glial tumor, this diagnosis was used to inform management decisions. While definitive treatment remains controversial for an aggressive tumor in this age range, the tumor board consensus was complete craniospinal radiotherapy.

\section{Case 6}

A 49-year-old male from an outside institution had a left frontal lesion that was subtotally resected. The histopathological differential diagnosis was PXA versus other high-grade glioma as it was not only superficial with compact growth and prominent eosinophilic granular bodies but also had frequent mitoses, microvascular proliferation, and necrotic areas. Methylation classification was pursued due to the differential diagnosis. The methylation class of the tumor was an IDH wildtype glioblastoma with a 0.99 calibrated score and the CNV plot showed EGFR amplification and PTEN loss. The integrated diagnosis was that of an IDH wildtype glioblastoma and the resulting significant change in management included concurrent chemoradiation and continued temozolomide.

\section{Case 7}

A 71-year-old female non-smoker presented with hemiparesis and an MRI showing a right frontal lesion having characteristics of a cystic primary glioma versus metastasis. After gross total resection, it was initially diagnosed as a TTF-1 positive metastatic high-grade neuroendocrine neoplasm with high cellularity, necrosis, minimal brain infiltration, and small cell phenotype. She received stereotactic radiosurgery postoperatively, fractionated 
radiotherapy plus cisplatin/etoposide for a 6-month recurrence, and surgery plus whole-brain radiotherapy for 12-month further progression. A primary tumor was not identified despite serial pan-imaging including chest CT scans, multiple negative biopsies (thyroid/breast nodule, lymph node, and uterine tissue), and laryngocolonoscopies.

The case was flagged for methylation analysis as the course of disease progression was unusual with no primary systemic cancer being identified. The methylation classification and integrated diagnosis was an IDH wildtype glioblastoma (calibrated score of 0.94) with a characteristic gain of chromosome 7 and loss of chromosome 10 on the $\mathrm{CNV}$ plot. She then received temozolomide but progression continued and she is deceased 20 months from the initial surgery. Regarding the TTF-1 positivity, staining remained positive in the recurrent tumor and TTF-1 positivity has been reported rarely in glioblastomas [15].

\section{Discussion}

DNA methylation profiling is an emerging powerful tool that can resolve diagnostic discrepancies and provide objective evidence to help classify challenging CNS tumor cases $[11,12,16,17]$. There is increasing support within both the neuro-pathology and neuro-oncology communities for the increasing integration of molecular markers into diagnosis and treatment $[6,18]$. Here, we show one of the first institutional experiences in rapidly adopting the methylation classifier and integrating it into practice to change the clinical management of brain tumor patients. We highlight that utilizing methylation testing in challenging CNS tumors not only refines diagnosis in $84 \%$ of the cases but also significantly impacts treatment decisions for a significant proportion (15\%) of patients. Early recognition of the value of methylation testing at our institution resulted in rapid adoption by the multidisciplinary team managing CNS tumors. The necessary steps for adoption included early acquisition of technology, training to build medical expertise, and implementation of quality assurance measures.

Overall, of the 55 CNS tumor cases with challenging diagnoses, $84 \%$ had a clinically meaningful adjustment to the histopathological diagnosis with key components being a change in diagnosis for $24 \%$, a resolved differential diagnosis for $31 \%$, and the validation of new molecular markers to help with refinement of tumor classification for $29 \%$. In the cohort of 1104 cases analyzed by the German Cancer Research Center that was initially used to validate the classifier, $12 \%$ received a change in diagnosis and $15 \%$ a molecular refinement [11]. In our series, we restricted the use of methylation profiling to challenging cases only and in this population, the utility and value of CNS tumor methylation classification were dramatically higher at $84 \%$. This result supports the use of methylation profiling in those cases where there is uncertainty in diagnosis or where clinical suspicion of an alternative diagnosis is raised, in order to validate traditional histopathological diagnoses.

More importantly, we show that a significant subset of patients (15\%) profiled experience impactful changes to their clinical management due to the additional diagnostic information. Unnecessary treatment and related sideeffects were avoided in $6.4 \%$ of all patients and insufficient inappropriate treatment could be avoided in an additional $6.4 \%$. The outlook on diagnosis was altered in another patient considering medically assisted death (MAID) based on the original diagnosis of an incurable glioblastoma. The decision to pursue MAID was reversed with the change in diagnosis after methylation profiling. Overall, avoiding unnecessary chemoradiation and associated risks/side effects, refining diagnosis to counsel the patients on outcome and overall quality of life, and choosing the best oncological treatment regimen are among the key points.

Furthermore, there is value to optimizing and streamlining molecular testing approaches and to ensure they are used in a judicious and cost-effective manner. Methylation classification and copy number plotting can be done with one array and can obtain results for IDH status, $1 \mathrm{p} / 19 \mathrm{q}$ codeletion status, and MGMT methylation status, as the results between tests for these molecular features and the results by methylation profiling are highly concordant [19-24]. Optimal candidates for methylation profiling are those with a pathological diagnostic challenge or with limited tissue after a small biopsy precluding the application of multiple single tests. In diagnostically challenging cases a subset of these results may be obtained prior to pursuing methylation profiling but the cost of other tests can be avoided by profiling, including IDH1/2 staining and sequencing, FISH testing for $1 \mathrm{p} / 19 \mathrm{q}$ codeletions in diffuse gliomas, and testing of MGMT methylation status in malignant gliomas. Avoiding unnecessary chemoradiotherapy treatment and unnecessary tests (i.e., tissue biopsies) to investigate uncertain diagnoses also significantly reduces care delivery costs. In our institution, methylation profiling costs approximately 550 USD per patient and, although the cost avoidance varies by case, this is substantially less than the expected cost of unnecessary tests and unnecessary chemoradiotherapy treatments. The role of methylation profiling is expected to expand as well, as new tumor subtypes by methylation signatures are identified such as the G-CIMP methylation pattern correlating with IDH mutation in glioma and its institutional role may expand [25].

A limitation of the methylation classifier is that it has an error rate of $1 \%$ and it is limited in distinguishing many grades II-III lesions, underlying the importance of the 
integrated diagnosis workflow that considers all pathological data [12]. The classifier determines MGMT status by a cutoff that maximizes the sum of the sensitivity and specificity, but there is emerging evidence of a more optimal clinically relevant cutoff that is significantly lower [14, 26]. Methylation turnaround times are variable depending on the institutional frequency of use but most are completed within 30 days and this time is decreasing with its expanding use. The median turnaround time of 25 days in our cohort is consistent with times seen by others [16].

\section{Conclusions}

Overall, this work substantiates the value of DNA methylation profiling for diagnostically challenging CNS tumor cases by demonstrating that a substantial proportion receives changes to their diagnosis and treatment decisions after profiling. It is an example of how new technology can be rapidly integrated into practice and adopted clinically to improve patient outcomes. This technology avoids unnecessary treatment and testing related to misdiagnosis in challenging cases of CNS tumors in addition to reducing overall costs associated with individual molecular testing. Widespread adoption of genome-wide DNA methylation profiling as a diagnostic platform is important in order to keep delivery of care nimble and cutting-edge, allowing us to offer the best care to our patients.

\section{Abbreviations}

CNS: Central nervous system; CNV: Copy number variant; DLGNT: Diffuse leptomeningeal glioneuronal tumor; DNET: Dysembryoplastic neuroepithelial tumor; FISH: Fluorescence in situ hybridization; FSRT: Fractionated stereotactic radiotherapy; FSRT: Single-dose stereotactic radiosurgery; GBM: Glioblastoma; IHC: Immunohistochemistry; MAID: Medically assisted death; NE: Neuroendocrine; NOS: Not otherwise specified; PXA: Pleomorphic xanthoastrocytoma; RT: Radiotherapy; RT: Temozolomide; SFT: Solitary fibrous tumor; UHN: University Health Network; WHO: World Health Organization

\section{Acknowledgements}

Not applicable.

\section{Authors' contributions}

SK, JAZ, YM, PD, KDA, and GZ contributed to the study design. SK, SM, PD, DGM, and GZ processed DNA tumor. JAZ, SS, FN, and GZ collected clinical data. SK, JAZ, YM, SM, SS, and FN analyzed the data. All authors interpreted the data, prepared and revised the manuscript. All authors read and approved the final manuscript.

\section{Funding}

This study was financed by our MacFeeters-Hamilton Grant.

\section{Availability of data and materials}

The datasets used and/or analyzed during the current study are available from the corresponding author on reasonable request.

\section{Ethics approval and consent to participate}

The study protocol was approved by the University Health Network (UHN) research ethics board in Toronto, Canada.

\section{Consent for publication}

Consent was obtained through standard institutional forms.

\section{Competing interests}

The authors declare that they have no competing interests.

\section{Author details}

'Division of Neurosurgery, University Health Network, University of Toronto, Toronto, Ontario, Canada. ${ }^{2}$ MacFeeters-Hamilton Center for Neuro-Oncology, Princess Margaret Cancer Center, Princess Margaret Cancer Research Tower, 101 College Street, 14th floor, Room 601, Toronto, ON M5G 1L7, Canada. 3 Laboratory Medicine Program, University Health Network, Toronto, Ontario, Canada. ${ }^{4}$ Department of Laboratory Medicine, St. Michael's Hospital, Toronto, Ontario, Canada. ${ }^{5}$ Laboratory of Pathology, Center for Cancer Research, National Cancer Institute, Building 10, Room 2S235, Bethesda, MD 20892-1500, USA.

Received: 12 July 2019 Accepted: 17 October 2019

Published online: 05 December 2019

\section{References}

1. Louis DN, Perry A, Reifenberger G, von Deimling A, Figarella-Branger D, Cavenee WK, et al. The 2016 World Health Organization Classification of Tumors of the Central Nervous System: a summary. Acta Neuropathol. 2016; 131(6):803-20

2. Sturm D, Orr BA, Toprak UH, Hovestadt V, Jones DTW, Capper D, et al. New Brain Tumor Entities Emerge from Molecular Classification of CNS-PNETs. Cell. 2016;164(5):1060-72.

3. Sturm D, Witt H, Hovestadt V, Khuong-Quang DA, Jones DT, Konermann C, et al. Hotspot mutations in H3F3A and IDH1 define distinct epigenetic and biological subgroups of glioblastoma. Cancer Cell. 2012;22(4):425-37.

4. Taylor MD, Northcott PA, Korshunov A, Remke M, Cho YJ, Clifford SC, et al. Molecular subgroups of medulloblastoma: the current consensus. Acta Neuropathol. 2012;123(4):465-72.

5. Pajtler KW, Witt H, Sill M, Jones DT, Hovestadt V, Kratochwil F, et al. Molecular Classification of Ependymal Tumors across All CNS Compartments, Histopathological Grades, and Age Groups. Cancer Cell. 2015;27(5):728-43.

6. Aldape K, Nejad R, Louis DN, Zadeh G. Integrating molecular markers into the World Health Organization classification of CNS tumors: a survey of the neuro-oncology community. Neuro-oncology. 2017;19(3):336-44.

7. Jones PA. Functions of DNA methylation: islands, start sites, gene bodies and beyond. Nat Rev Genet. 2012;13(7):484-92.

8. Fernandez AF, Assenov Y, Martin-Subero Jl, Balint B, Siebert R, Taniguchi $H$, et al. A DNA methylation fingerprint of 1628 human samples. Genome Res. 2012:22(2):407-19.

9. Hao X, Luo H, Krawczyk M, Wei W, Wang W, Wang J, et al. DNA methylation markers for diagnosis and prognosis of common cancers. Proc Natl Acad Sci U S A. 2017:114(28):7414-9.

10. Moran S, Martinez-Cardus A, Sayols S, Musulen E, Balana C, Estival-Gonzalez A, et al. Epigenetic profiling to classify cancer of unknown primary: a multicentre, retrospective analysis. The Lancet Oncology. 2016;17(10):1386-95.

11. Capper D, Jones DTW, Sill M, Hovestadt V, Schrimpf D, Sturm D, et al. DNA methylation-based classification of central nervous system tumours. Nature. 2018;555(7697):469-74.

12. Capper D, Stichel D, Sahm F, Jones DTW, Schrimpf D, Sill M, et al. Practical implementation of DNA methylation and copy-number-based CNS tumor diagnostics: the Heidelberg experience. Acta Neuropathol. 2018;136(2):181-210.

13. Shirahata M, Ono T, Stichel D, Schrimpf D, Reuss DE, Sahm F, et al. Novel, improved grading system(s) for IDH-mutant astrocytic gliomas. Acta Neuropathol. 2018;136(1):153-66.

14. Bady P, Sciuscio D, Diserens AC, Bloch J, van den Bent MJ, Marosi C, et al. MGMT methylation analysis of glioblastoma on the Infinium methylation BeadChip identifies two distinct CpG regions associated with gene silencing and outcome, yielding a prediction model for comparisons across datasets, tumor grades, and CIMP-status. Acta Neuropathol. 2012;124(4):547-60.

15. Pratt $D$, Afsar $N$, Allgauer $M$, Fetsch $P$, Palisoc $M$, Pittaluga $S$, et al. Reevaluating TTF-1 immunohistochemistry in diffuse gliomas: Expression is clone-dependent and associated with tumor location. Clin Neuropathol. 2017;36(6):263-71.

16. Jaunmuktane Z, Capper D, Jones DTW, Schrimpf D, Sill M, Dutt M, et al. Methylation array profiling of adult brain tumours: diagnostic outcomes in a large, single centre. Acta neuropathologica communications. 2019;7(1):24. 
17. Bachli H, Ecker J, van Tilburg C, Sturm D, Selt F, Sahm F, et al. Molecular diagnostics in pediatric brain tumors: impact on diagnosis and clinical decision-making — a selected case series. Klin Padiatr. 2018;230(6):305-13.

18. Louis DN, Perry A, Burger P, Ellison DW, Reifenberger G, von Deimling A, et al. International Society Of Neuropathology--Haarlem consensus guidelines for nervous system tumor classification and grading. Brain pathology (Zurich, Switzerland). 2014;24(5):429-435.

19. Velazquez Vega JE, Brat DJ. Incorporating advances in molecular pathology into brain tumor diagnostics. Adv Anat Pathol. 2018;25(3):143-71.

20. Feber A, Guilhamon P, Lechner M, Fenton T, Wilson GA, Thirlwell C, et al. Using high-density DNA methylation arrays to profile copy number alterations. Genome Biol. 2014;15(2):R30.

21. Wiestler B, Capper D, Hovestadt V, Sill M, Jones DT, Hartmann C, et al. Assessing CpG island methylator phenotype, 1p/19q codeletion, and MGMT promoter methylation from epigenome-wide data in the biomarker cohort of the NOA-04 trial. Neuro-oncology. 2014;16(12):1630-8.

22. Weller M, Stupp R, Reifenberger G, Brandes AA, van den Bent MJ, Wick W, et al. MGMT promoter methylation in malignant gliomas: ready for personalized medicine? Nat Rev Neurol. 2010;6(1):39-51.

23. van den Bent MJ, Weller M, Wen PY, Kros JM, Aldape K, Chang S. A clinical perspective on the 2016 WHO brain tumor classification and routine molecular diagnostics. Neuro-oncology. 2017;19(5):614-24.

24. Preusser M, Capper D, Hartmann C. IDH testing in diagnostic neuropathology: review and practical guideline article invited by the EuroCNS research committee. Clin Neuropathol. 2011;30(5):217-30.

25. Noushmehr H, Weisenberger DJ, Diefes K, Phillips HS, Pujara K, Berman BP, et al. Identification of a CPG island methylator phenotype that defines a distinct subgroup of glioma. Cancer Cell. 2010;17(5):510-22.

26. Hegi ME, Genbrugge E, Gorlia T, Stupp R, Gilbert MR, Chinot OL, et al. MGMT promoter methylation cutoff with safety margin for selecting glioblastoma patients into trials omitting temozolomide: a pooled analysis of four clinical trials. Clin Cancer Res. 2019;25(6):1809-16.

\section{Publisher's Note}

Springer Nature remains neutral with regard to jurisdictional claims in published maps and institutional affiliations.

Ready to submit your research? Choose BMC and benefit from:

- fast, convenient online submission

- thorough peer review by experienced researchers in your field

- rapid publication on acceptance

- support for research data, including large and complex data types

- gold Open Access which fosters wider collaboration and increased citations

- maximum visibility for your research: over $100 \mathrm{M}$ website views per year

At $\mathrm{BMC}$, research is always in progress.

Learn more biomedcentral.com/submissions 